\title{
Three Scenarios for Interest Rates in the Transition to Normalcy
}

\author{
Diana A. Cooke and William T. Gavin
}

In this article, time-series models are developed to represent three alternative, potential monetary policy regimes as monetary policy returns to normal. The first regime is a return to the high and volatile inflation rate of the 1970s. The second regime, the one expected by most Federal Reserve officials and business economists, is a return to the credible low inflation policy that characterized the U.S. economy from 1983 to 2007, a period known as the Great Moderation. The third regime is one in which policymakers keep policy interest rates at or near zero for the foreseeable future; Japanese data are used to estimate this regime. These time-series models include four variables: per capita gross domestic product growth, consumer price index inflation, the policy rate, and the 10-year government bond rate. These models are used to forecast the U.S. economy from 2008 through 2013 and represent the possible outcomes for interest rates that may follow the return of monetary policy to normal. Here, "normal" depends on the policy regime that follows the liftoff of the federal funds rate target expected in mid-2015. (JEL E43, E47, E52, E58, E65)

Federal Reserve Bank of St. Louis Review, First Quarter 2015, 97(1), pp. 1-24.

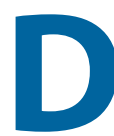

uring the fourth quarter of 2008 , while in the process of rescuing a few large financial firms following the Lehman Brothers bankruptcy, the Federal Reserve added about $\$ 600$ billion in excess reserves to the banking system. Throughout 2007, the banking system had operated with less than $\$ 5$ billion. This action drove the interest rate on bank reserves (aka the federal funds rate or policy rate) below the Federal Open Market Committee's (FOMC) target rate of 2 percent. By the first Friday in December 2008, the effective federal funds rate had fallen to 12 basis points. On December 16, 2008, the FOMC then set the official federal funds rate target at a range of 0 to 0.25 percent, where it remains to this day. With the policy rate effectively at zero and the banking system flooded with excess reserves, the FOMC has tried to ease monetary conditions through two related policies: (i) forward guidance promises of maintaining the current policy rate even further into the future and (ii) large-scale purchases of long-term Treasury debt and agency mortgagebacked securities, which effectively exerts downward pressure on long-term interest rates. As of June 2014, this latter policy has increased the total of excess reserves to $\$ 2.6$ trillion.

Diana A. Cooke is a research associate and William T. Gavin is a former vice president, economist, and editor-in-chief of Review at the Federal Reserve Bank of St. Louis. The authors thank Kevin Kliesen and Yi Wen for helpful comments.

(c) 2015, The Federal Reserve Bank of St. Louis. The views expressed in this article are those of the author(s) and do not necessarily reflect the views of the Federal Reserve System, the Board of Governors, or the regional Federal Reserve Banks. Articles may be reprinted, reproduced, published, distributed, displayed, and transmitted in their entirety if copyright notice, author name(s), and full citation are included. Abstracts, synopses, and other derivative works may be made only with prior written permission of the Federal Reserve Bank of St. Louis. 


\section{Cooke and Gavin}

Within the Federal Reserve System, this situation is considered temporary and the FOMC is now debating strategies that would return both the balance sheet and the policy rate to normal. When the economy and monetary policy eventually return to normal, excess reserves would be expected to return to levels observed before the financial crisis. A useful definition of "normal" can be taken from the December 2014 FOMC long-run forecasts of real GDP growth (2.0 to 2.3 percent), inflation ( 2 percent), the unemployment rate (5.2 to 5.5 percent), and the policy rate ( 3.5 to 4.0 percent). ${ }^{1}$ The effects of reducing excess reserves will depend on how interest rates change during the transition to normalcy. The level and volatility of interest rates will depend on the public's beliefs about future monetary policy. Carpenter et al. (2013) provide an excellent overview of the Fed's balance sheet and describe three exit strategies based on FOMC policy statements. Their projections of the Fed's balance sheet and its net income are conditioned on assumptions about future interest rates.

The "Lucas critique," a well-known econometric problem, is associated with simulating an economy under alternative policy assumptions (Lucas, 1976). The Carpenter et al. (2013) simulations are based on the implicit assumption that the U.S. economy has had one stable policy regime from about 1983 to the present and that the transition period will be an extension of this same policy regime. In this article, we discard this assumption and allow the periods with credibility, no credibility, and a zero policy rate to be separate regimes with different econometric properties.

Distinguishing between regimes is important because the major concerns surrounding the exit strategy for monetary policy arise from the interest rate implications of the transition to a separate policy regime. For example, in our judgment the "taper tantrum" of 2013 was a typical interest rate response that would naturally be associated with moving from a zero interest rate policy (ZIRP) to the credible monetary policy regime in place between 1983 and 2007, a period known as the Great Moderation. In addition, some economists and policymakers worry that the ZIRP regime will eventually lead to a loss of credibility for the Fed and a return to the high-inflation regime in the United States from about 1965 through $1979 .{ }^{2}$

Predicting interest rates during the transition to normalcy is complicated because it requires predicting the regime that will be in place at the end of the transition. How high interest rates are likely to rise and how likely the yield curve is to become inverted depends on people's beliefs about the policy regime. We develop three scenarios based on alternative assumptions about Federal Reserve policy.

We use a data-based scheme to identify time-series models for interest rates associated with each regime. Data from unique episodes before 2008 are used to estimate the models, which are then simulated to forecast the U.S. economy during the 2008-13 period from the point of view of 2007:Q4. The purpose of these forecasts is simply to illustrate how well the alternative regimes can explain interest rates during the past six years. Then starting from the point of view of 2013:Q4, the forecasts show interest rate expectations for the next few years.

The time-series model for each scenario generates interest rates assumed to be typical of the relevant policy regime. For example, we ask what would happen to interest rates if the Fed lost credibility for price stability, as it did in the period following the breakdown of the dollar standard agreed to at Bretton Woods after World War II. Our results show that inflation and 
interest rates would become unacceptably high and volatile, as they did in the 1970s. We consider this scenario and two others: one based on policy during the Great Moderation (the U.S. economy from 1983 to 2007) and the other based on the ZIRP in Japan, where the monetary policy rate was held at or below $1 / 2$ percent from 1995 through 2007.

\section{THREE SCENARIOS FOR MONETARY POLICY}

We consider three scenarios representing three different policy regimes:

- The first scenario assumes that the Fed loses credibility for its inflation objective, as it did in the 1970s, and inflation accelerates. We use U.S. data from 1965:Q1 to 1979:Q3 to estimate the No Credibility model.

- The second scenario assumes that the Fed has credibility and operates policy to achieve price stability (low inflation) as it did from 1987 to 2007. We use U.S. data from 1983:Q1 to 2007:Q4 to estimate the Credibility model.

- The third scenario assumes the Fed keeps the policy rate at or near zero permanently. The credibility for the 2 percent inflation objective is dominated by credibility for its ZIRP. We use Japanese data from 1995:Q1 to 2007:Q4 to estimate the ZIRP model.

The statistical relationships determining per capita output, inflation, and interest rates are assumed to depend on the monetary policy regime, which is characterized by the timeseries models developed later in this article. We recognize that monetary policy is not the only reason for differences in the time-series properties of the data among our alternative sample periods. There are structural differences between the U.S. economy and the Japanese economy, as well as between the early U.S. period and the later one. For this reason, we do not emphasize results for the real economy. Our key assumption is that monetary policy, through its determination of the inflation trend, is the dominant factor driving nominal interest rates. ${ }^{3}$

We examine three periods corresponding to the three distinctly different monetary policy regimes. We review the historical experience to clarify how credibility matters for interest rates and inflation. Then we use our models to forecast inflation and interest rates over the financial crisis period to evaluate the range of uncertainty that may arise during a transition to normalcy.

\section{Three Regimes (The Same Time-Series Model Estimated Over Different Episodes)}

Our basic model in all three policy scenarios is a vector autoregression (VAR) including four quarterly time series: per capita gross domestic product (GDP) growth, consumer price index (CPI) inflation, a short-term policy rate, and the 10-year government bond rate. The policy rate for the United States is the overnight federal funds rate. For Japan, it is the call money rate. ${ }^{4}$

Our model produces a four-quarter-ahead forecast. It is written as

$$
Y_{t+3}=A(L) Y_{t-1}+e_{t+3}
$$




\section{Cooke and Gavin}

where

$$
Y_{t}=\left(\begin{array}{c}
G D P_{t} \\
C P I_{t} \\
R S_{t} \\
R L_{t}
\end{array}\right) \text { and } e_{t}=\left(\begin{array}{c}
e_{g d p, t} \\
e_{c p i, t} \\
e_{r s, t} \\
e_{r l, t}
\end{array}\right),
$$

where $G D P_{t}$ is real GDP growth minus population growth, $C P I_{t}$ is the four-quarter change in the CPI, $R S_{t}$ is the policy rate, and $R L_{t}$ is the 10 -year government bond rate. We assume that the error process is multivariate normal $e_{t} \sim N(0, \Sigma)$. We include the four-quarter forecast horizon rather than a one-quarter horizon because we are mainly interested in medium-term forecasts and the four-quarter specification produces better forecasts at longer horizons. Our models have identical structures, but the estimated parameters differ across the three scenarios (No Credibility, Credibility, and ZIRP) because the data used to estimate the models are from three episodes with very different monetary policy environments.

\section{No Credibility Scenario: 1965-79}

During the 1970s, the United States experienced a period of accelerating inflation known as the Great Inflation. ${ }^{5}$ The top panel of Figure 1 shows that CPI inflation rose in fits and starts from just under 2 percent in 1965 to 12.2 percent in September 1979. This period was often characterized as an era of stop-go monetary policy. When inflation accelerated, the FOMC would raise the policy rate high enough to slow inflation. The relatively high policy rate would lower aggregate spending, reduce the demand for labor, and lead to a recession. The FOMC would then switch gears, lowering the policy rate sharply to stimulate spending and job growth. The stop-go nature of this policy is evident in the bottom panel of Figure 1, which shows the federal funds rate and the 10-year government bond rate from 1965 through 1979.

The relationship between the policy rate and the bond rate during the pre-1980 period displays three distinct features. First, both interest rates display rising trends and, on average, are roughly equal; the policy rate averaged just 0.6 percent less than the bond rate. Second, the policy rate was sometimes much higher than the bond rate. Third, periods with a relatively low policy rate were followed by higher inflation and inflation expectations, reflected in rising bond rates.

The lack of credibility required setting the policy rate above the bond rate to reduce inflation expectations. When the FOMC raised the policy rate too slowly, inflation expectations would rise to match the rise in the interest rate with no dampening effect on either the economy or inflation. The lack of credibility meant that to succeed in lowering inflation, the FOMC had to raise the policy rate high enough to slow the economy. This led to a belief that stabilizing inflation would likely lead to high unemployment. A corollary to this belief was that low interest rates would raise inflation, and, at the same time, lower the unemployment rate. What has not been generally recognized is that these dynamic relationships came to be part of conventional wisdom in macroeconomics during a time when the Fed had no credibility for its inflation objective. 


\section{Figure 1}

\section{United States without Fed Credibility (1965-79)}

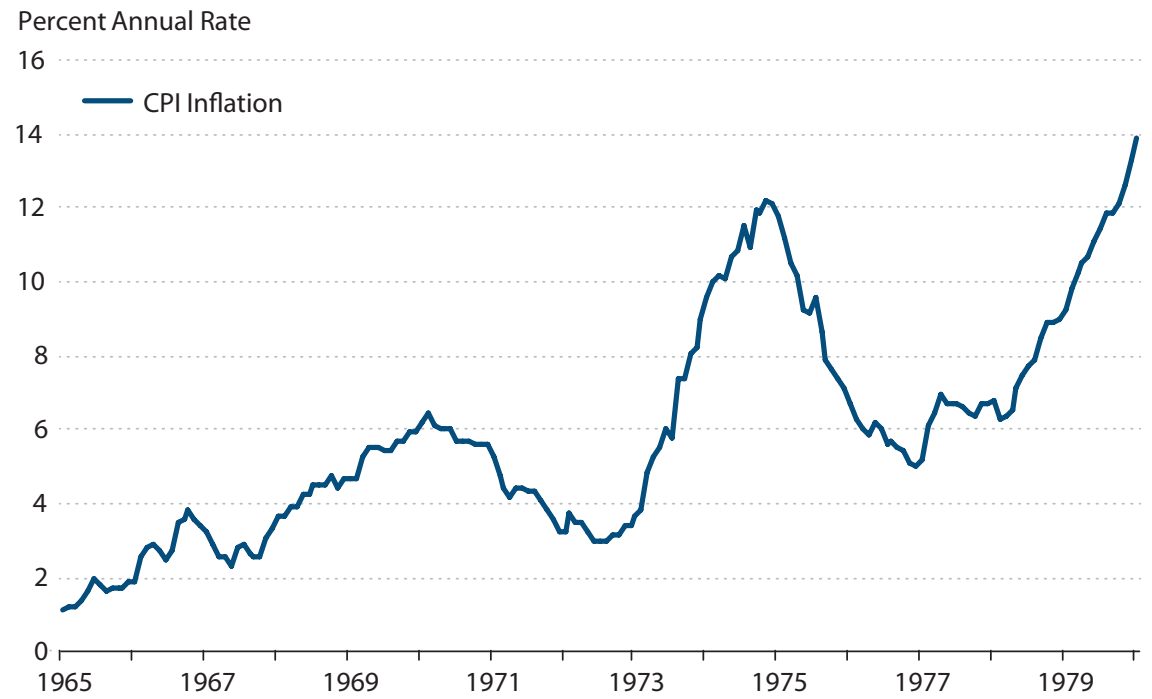

\section{Percent}

16

14 Federal Funds Rate

14 - 10-Year Government Bond Rate

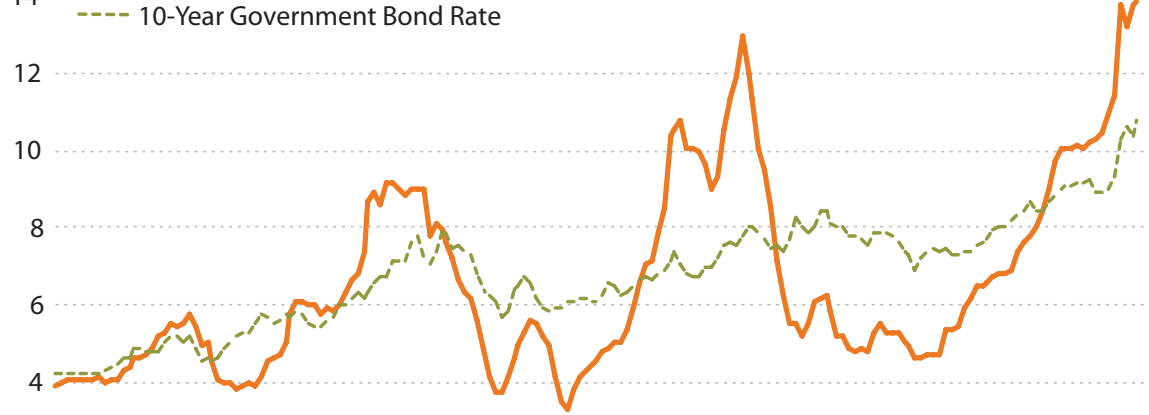

2

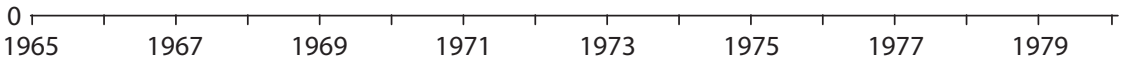

NOTE: Inflation is measured as the change over the previous year.

SOURCE: Data from FRED ${ }^{\oplus}$, Federal Reserve Economic Data, Federal Reserve Bank of St. Louis: Consumer Price Index for All Urban Consumers: All Items [CPIAUCSL]; U.S. Bureau of Labor Statistics; http://research.stlouisfed.org/fred2/series/ CPIAUCSL; accessed January 1, 2015. 10-Year Treasury Constant Maturity Rate [GS10]; Board of Governors of the Federal Reserve System; http://research.stlouisfed.org/fred2/series/GS10; accessed January 1, 2015. Effective Federal Funds Rate [FEDFUNDS]; Board of Governors of the Federal Reserve System; http://research.stlouisfed.org/fred2/series/FEDFUNDS; accessed January 1, 2015. 
Table $1 \mathrm{~A}$

No Credibility Model

\begin{tabular}{lcccc} 
& $G D P_{t+3}$ & $C P I_{t+3}$ & $R S_{t+3}$ & $R L_{t+3}$ \\
\hline$G D P_{t-1}$ & $-0.16^{*}$ & $0.65^{*}$ & 0.66 & $0.23^{* *}$ \\
$C P I_{t-1}$ & 0.01 & 0.54 & -0.03 & $0.25^{*}$ \\
$R S_{t-1}$ & -1.15 & 0.51 & 0.51 & $0.04^{*}$ \\
$R L_{t-1}$ & 0.42 & -5.74 & 0.84 & 0.64 \\
Constant & 7.23 & 0.79 & -3.43 & 0.57 \\
Adjusted $R^{2}$ & 0.67 & 1.45 & 0.56 & 0.83 \\
SE equation & 1.46 & 6.37 & 1.79 & 0.62 \\
Mean dependent & 2.39 & 3.15 & 6.93 & 7.05 \\
SD dependent & 2.54 & & 2.70 & 1.52 \\
Included observations & 59 & & &
\end{tabular}

Residual correlation matrix (SE on diagonal)

\begin{tabular}{lcccc} 
& GDP & CPI & RS & RL \\
\hline GDP & 1.46 & - & - & - \\
CPI & -0.03 & 1.45 & - & - \\
RS & 0.13 & 0.77 & 1.79 & - \\
RL & 0.24 & 0.55 & 0.78 & 0.62
\end{tabular}

NOTE: RS, short-run (policy) rate; RL, long-run (bond) rate; SD, standard deviation; SE, standard error. * and ** indicate significance at the 10 percent and 5 percent levels, respectively.

We use U.S. data from 1965:Q1 through 1979:Q3 for the No Credibility model. For this and the other models, we find that the best lag length was just one quarter based on the Schwartz Bayesian information criterion. Table $1 \mathrm{~A}$ lists the estimates of the model and summary statistics. The standard errors in the per capita GDP growth, inflation, policy rate, and bond rate equations are 1.46, 1.45, 1.79, and 0.62 percent, respectively. These standard errors are important because they influence the inherent uncertainty in the forecasts.

The other major factor influencing the uncertainty in the forecast is the implication for the long-run trend. Table 2 presents the long-run mean forecasts for each model starting from the initial conditions in 2007 and 2013. These are dynamic forecasts under the assumption that there are no further shocks over the forecast period. The number of years to convergence depends on initial conditions and how quickly the models' equations converge to their longrun trends. ${ }^{6}$ In the No Credibility model, starting from 2007 (2013) initial conditions, per capita GDP growth converges to -6.7 percent in 222 (224) years. The CPI inflation rate converges to 34.5 percent in 283 (286) years, the federal funds rate converges to 22.0 percent in 238 (240) years, and the bond rate converges to 23.7 percent in 335 (338) years. When we start with initial conditions in 2013, the long-run values are the same but the years to convergence are a bit longer because we start further from the long-run values. 
Table 1B

Credibility Model

\begin{tabular}{lcccc} 
& $G D P_{t+3}$ & $C P I_{t+3}$ & $R S_{t+3}$ & $R L_{t+3}$ \\
\hline$G D P_{t-1}$ & $-0.03^{*}$ & $0.04^{*}$ & $0.31^{*}$ & $-0.06^{*}$ \\
$C P I_{t-1}$ & -0.85 & 0.21 & -0.05 & -0.17 \\
$R S_{t-1}$ & -0.20 & $0.17^{*}$ & 0.52 & $0.13^{*}$ \\
$R L_{t-1}$ & 0.63 & $-0.06^{*}$ & 0.25 & $0.79^{*}$ \\
Constant & 1.66 & 1.94 & 0.12 & 1.17 \\
Adjusted $R^{2}$ & 0.32 & 0.16 & 0.68 & 0.76 \\
SE equation & 1.36 & 0.98 & 1.37 & 1.07 \\
Mean dependent & 2.18 & 3.15 & 5.27 & 6.66 \\
SD dependent & 1.64 & 1.07 & 2.42 & 2.20 \\
Included observations & 100 & & &
\end{tabular}

Residual correlation matrix (SE on diagonal)

\begin{tabular}{lcccc} 
& GDP & CPI & RS & RL \\
\hline GDP & 1.36 & - & - & - \\
CPI & -0.07 & 0.98 & - & - \\
RS & 0.54 & 0.39 & 1.37 & - \\
RL & 0.57 & 0.43 & 0.65 & 1.07
\end{tabular}

NOTE: RS, short-run (policy) rate; RL, long-run (bond) rate; SD, standard deviation; SE, standard error. * and ** indicate significance at the 10 percent and 5 percent levels, respectively.

These long-run values suggest that the No Credibility policy regime is headed toward the type of hyperinflation that has occurred in third-world countries. Such a policy regime is politically unsustainable. Either the government changes the policy or the people change the government. In the United States, this policy regime spanned less than two decades. Political pressure from home and abroad led the Federal Reserve to abandon this regime and adopt one with a credible inflation policy (see Lindsey, Rasche, and Orphanides, 2013).

\section{Credibility Scenario: 1983-2007}

In October 1979, the Federal Reserve, under then-Chair Paul Volcker, adopted a new policy based on targeting the money supply to restore price stability. This new procedure lasted three years during which interest rates were very high and volatile. At the end of the three years, the inflation rate had fallen from double digits in 1980 to around 3 percent at the end of 1982. The Fed then switched from targeting the money supply to an indirect form of targeting the interest rate. By the time Alan Greenspan became the Fed chair in June 1987, the Fed had gained credibility for its inflation policy. The period of low inflation and credible monetary policy was accompanied by dramatic changes in the relationship between the policy rate 
Table 1C

ZIRP Model

\begin{tabular}{lcccc} 
& $G D P_{t+3}$ & $C P I_{t+3}$ & $R S_{t+3}$ & $R L_{t+3}$ \\
\hline$G D P_{t-1}$ & 0.01 & $0.22^{*}$ & $0.05^{* *}$ & $0.02^{* *}$ \\
$C P I_{t-1}$ & -1.07 & 0.27 & $0.06^{* *}$ & $-0.05^{*}$ \\
$R S_{t-1}$ & -0.31 & -0.28 & $0.02^{*}$ & 0.41 \\
$R L_{t-1}$ & 0.29 & 0.47 & $0.16^{* *}$ & 0.42 \\
Constant & 0.96 & -1.05 & -0.18 & 0.77 \\
Adjusted $R^{2}$ & 0.22 & 0.31 & 0.60 & 0.63 \\
SE equation & 1.37 & 0.73 & 0.14 & 0.34 \\
Mean dependent & 1.49 & 0.06 & 0.20 & 1.68 \\
SD dependent & 1.55 & 0.87 & 0.22 & 0.56 \\
Included observations & 51 & & &
\end{tabular}

Residual correlation matrix (SE on diagonal)

\begin{tabular}{lcccc} 
& GDP & CPI & RS & RL \\
\hline GDP & 1.37 & - & - & - \\
CPI & -0.11 & 0.73 & - & - \\
RS & 0.20 & 0.44 & 0.14 & - \\
RL & 0.42 & -0.02 & 0.10 & 0.34
\end{tabular}

NOTE: RS, short-run (policy) rate; RL, long-run (bond) rate; SD, standard deviation; SE, standard error. * and ** indicate significance at the 10 percent and 5 percent levels, respectively.

and the bond rate, as shown in Figure 2. Note the contrast from the earlier period: The CPI inflation trend stabilized at about 3 percent rather quickly, but the trend in interest rates fell only gradually as inflation expectations lagged behind the actual decline in the inflation rate.

An interesting event occurred after September 2, 1992: The FOMC, worried about low job growth in a slow recovery, decided to set the policy rate at 3 percent, a rate approximately equal to the perceived trend in inflation. It was believed that such a low interest rate would cause higher inflation and, in October 1993, the bond rate began to rise from a low of 5.3 percent. The FOMC began to raise the policy rate in February 1994 but did not need to raise it above the bond rate to end this brief inflation scare. ${ }^{7}$ The policy rate was raised to 6 percent in early 1995, but by then the bond rate had already begun to retreat from its peak at just under 8 percent in November 1994. On a 12-month moving average basis, the CPI inflation rate peaked at 2.9 percent in August 1994. During this entire episode, there were only a few instances when the policy rate was as high as the bond rate. On average, over the 1983-2007 sample period, the policy rate was 1.6 percentage points below the bond rate.

Table 1B presents the estimates of our Credibility model. For this period, the best lag structure in the VAR is also one quarter. The standard errors in the per capita GDP growth, infla- 


\section{Table 2}

\section{Long-Run Properties of Forecasting Models}

\begin{tabular}{|c|c|c|c|c|}
\hline & GDP & CPI & RS & $\mathbf{R L}$ \\
\hline \multicolumn{5}{|l|}{ No Credibility } \\
\hline Long-run value & -6.7 & 34.5 & 22.0 & 23.7 \\
\hline Years to convergence from 2007 initial conditions & 222 & 283 & 238 & 335 \\
\hline Years to convergence from 2013 initial conditions & 224 & 286 & 240 & 338 \\
\hline \multicolumn{5}{|l|}{ Credibility } \\
\hline Long-run value & 1.5 & 2.9 & 3.4 & 4.8 \\
\hline Years to convergence from 2007 initial conditions & 8 & 12 & 21 & 15 \\
\hline Years to convergence from 2013 initial conditions & 19 & 24 & 24 & 26 \\
\hline \multicolumn{5}{|l|}{ ZIRP } \\
\hline Long-run value & 1.5 & -0.1 & 0.1 & 1.5 \\
\hline Years to convergence from 2007 initial conditions & 9 & 5 & 7 & 6 \\
\hline Years to convergence from 2013 initial conditions & 7 & 5 & 2 & 3 \\
\hline
\end{tabular}

tion, policy rate, and bond rate equations are $1.36,0.98,1.37$, and 1.07 percent, respectively. Note that these standard errors are slightly smaller than those in the No Credibility model for the per capita GDP growth, inflation, and the policy rate equations but are actually larger for the bond rate equation. The reduction in uncertainty associated with the Credibility model stems largely from the much-improved properties of the long-run trends.

The middle panel of Table 2 presents the long-run mean forecasts for the Credibility model starting from initial conditions in 2007 and 2013. In the model starting from 2007 (2013) initial conditions, the per capita GDP growth rate converges to 1.5 percent in 8 (19) years, the inflation rate converges to 2.9 percent in 12 (24) years, the policy rate converges to 3.4 percent in 21 (24) years, and the bond rate converges to 4.8 percent in 15 (26) years. The key difference between the Credibility model and the No Credibility model is not in the short-run volatility but rather in the long-run trends for interest rates and inflation. Inflation and interest rates converge toward much lower values when policy is credible than when it is not.

\section{ZIRP Scenario: 1995-2007}

Our third scenario is an environment in which the policy rate is held at or near zero for an extended period. From the public's point of view, the monetary policy regime changes from having credibility for a 2 percent inflation target to also having credibility for promising to keep the policy rate near zero. A problem can arise if this promise remains in effect during the economic recovery. In this case, real returns are expected to be positive if the economy recovers.

In any equilibrium, the Fisher equation must hold: That is, the nominal interest rate must equal the real return plus the expected inflation rate. If the central bank holds the nominal 


\section{Cooke and Gavin}

\section{Figure 2}

\section{United States with Fed Credibility (1983-2013)}

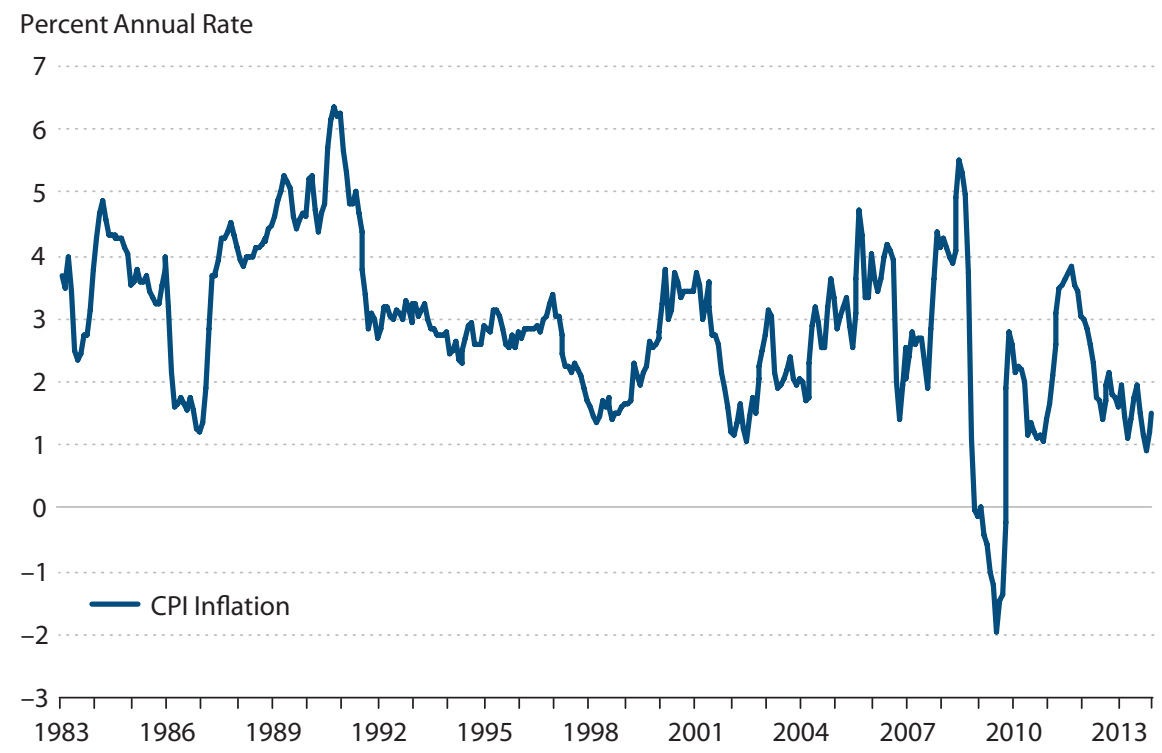

Percent

16

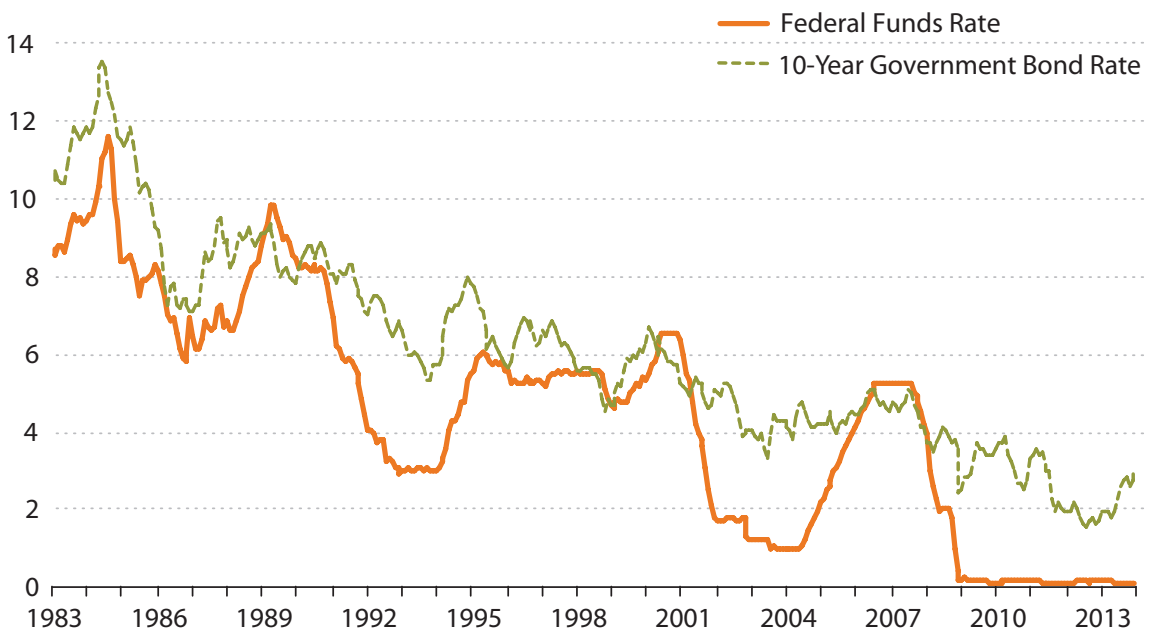

NOTE: Inflation is measured as the change over the previous year.

SOURCE: Data from FRED ${ }^{\circledR}$, Federal Reserve Economic Data, Federal Reserve Bank of St. Louis: Consumer Price Index for All Urban Consumers: All Items [CPIAUCSL]; U.S. Bureau of Labor Statistics; http://research.stlouisfed.org/fred2/series/ CPIAUCSL; accessed January 1, 2015. 10-Year Treasury Constant Maturity Rate [GS10]; Board of Governors of the Federal Reserve System; http://research.stlouisfed.org/fred2/series/GS10; accessed January 1, 2015. Effective Federal Funds Rate [FEDFUNDS]; Board of Governors of the Federal Reserve System; http://research.stlouisfed.org/fred2/series/FEDFUNDS; accessed January 1, 2015. 
interest rate (federal funds rate/policy rate) at zero while the economy is recovering, equilibrium dynamics will exert downward pressure on inflation. Over extended periods, a ZIRP is not consistent with a positive inflation target. The two policy objectives can persist only if real returns continue to be negative. ${ }^{8}$

A ZIRP can be a trap if inflation is below target, the economy is recovering, and policymakers believe that promising to hold interest rates low in the future will raise inflation. The 2 percent inflation target is not consistent with the zero interest rate (Japan's -0.1 percent inflation trend appears to be compatible with the ZIRP regime). In a growing economy, the $Z I R P$ regime will lead to negative inflation. Policymakers will not want to raise interest rates because many believe that even small increases can have large negative effects on the real economy. For a good example of this belief applied to the Japanese experience cited here, see Ito and Mishkin (2004), who describe the hike in the policy rate from 2 basis points to 25 basis points in August 2000 as a "clear mistake." This hike occurred as many of the Japanese policymakers wanted a return to normalcy. Economic news had been positive-but not conclusiveleading to a typical hawks-versus-doves debate. Ito and Mishkin (2004, p. 146) write,

\begin{abstract}
Almost as soon as the interest rate was raised in August [2000], the Japanese economy entered into a recession. It was not known at the time, but the official date for the peak of the business cycle turned out to be October 2000. The growth rate of 2000:III turned negative, which was offset to some extent by a brief recovery in 2000:IV. But, as the economy turned into a recession, the criticism of the Bank of Japan's actions became stronger.
\end{abstract}

This sort of narrative, which is common in the financial press, has a chilling effect on any attempt to raise interest rates before the central bank is certain that the economy has reached full employment. In fact, there is no empirical evidence that such small changes in the money market rate have any measurable or sustainable effect on the real economy. ${ }^{9}$ Moreover, every recovery is associated with uncertainty and fluctuations in news that drive observers from pillar to post. One day in the economic news there are optimistic reports about the recovery, and the next day there are worries that the economy will slide back into a recession. Such worries keep the policy rate at zero.

Since the United States has no earlier period with such a ZIRP regime, we use data from the Japanese economy for the 1995:Q1-2007:Q4 period to estimate the ZIRP model. ${ }^{10}$ Figure 3 shows the Japanese experience with CPI inflation and interest rates. The inflation rate, although slightly negative on average, appears to fluctuate around zero. In October 1995, the Japanese bond rate was 4.6 percent but fell quickly to 2 percent and continued to drift even lower after 2000 . The policy rate had been set low, at 2.25 percent, to try to stimulate the economy in 1995. However, further economic weakness led the Bank of Japan to lower the rate to $1 / 2$ percent by the end of the year and to nearly zero in 1999 (the beginning of the official ZIRP policy). Although there have been periods when the rate was raised slightly, bad incoming news about the economy and slightly negative inflation eventually led the Japanese policymakers to lower the rate back near zero.

Table 1C shows the ZIRP model estimates. For the 1995:Q1-2007:Q4 period in Japan, the best lag structure is, again, just one quarter. The standard errors in the per capita GDP growth, inflation, policy rate, and bond rate equations are $1.37,0.73,0.14$, and 0.34 percent, respectively. 


\section{Cooke and Gavin}

\section{Figure 3}

\section{Japan with a ZIRP (1995-2013)}
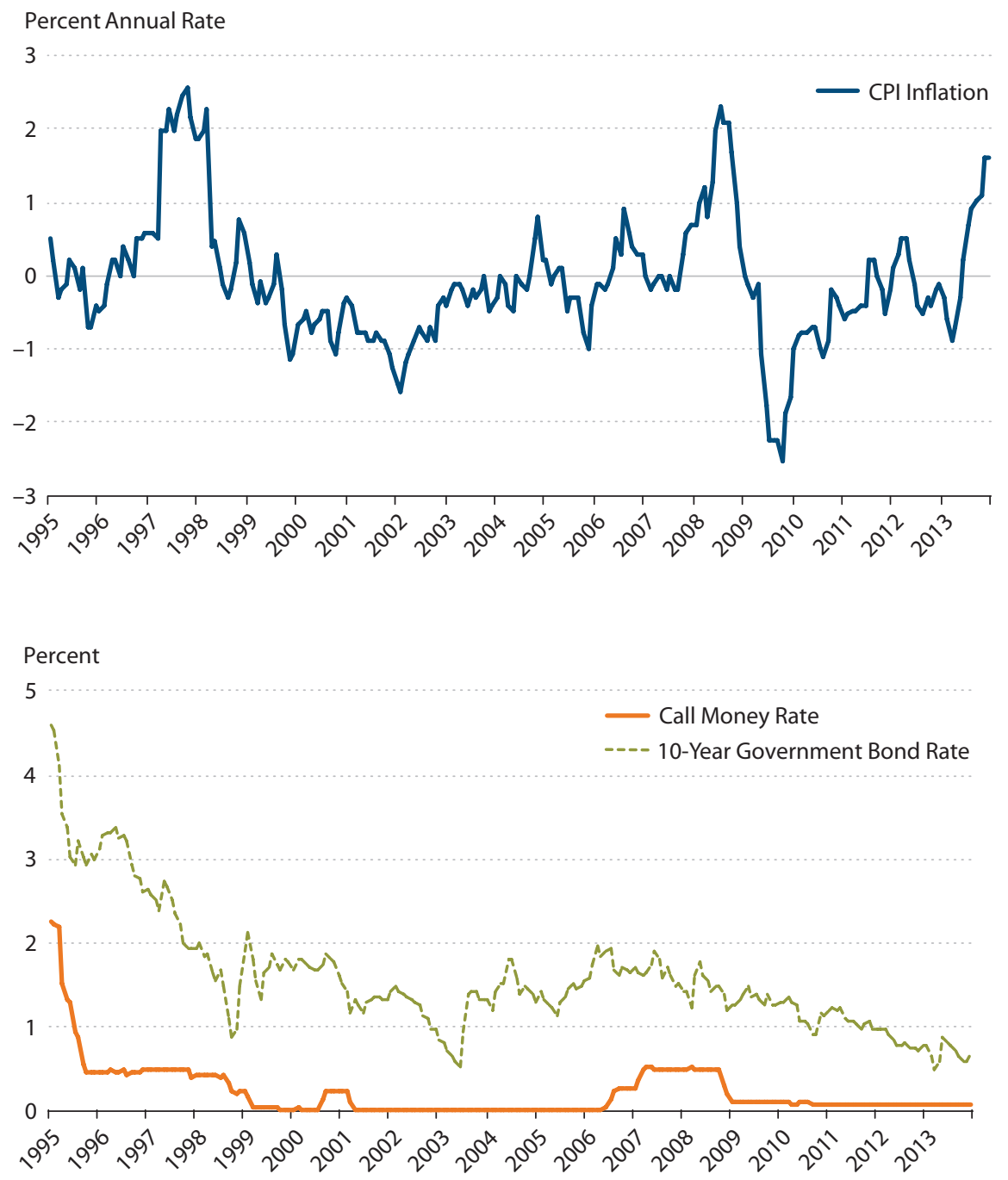

NOTE: Inflation is measured as the change over the previous year.

SOURCE: Data from FRED ${ }^{\circledR}$, Federal Reserve Economic Data, Federal Reserve Bank of St. Louis: Consumer Price Index of All Items in Japan [JPNCPIALLMINMEI]; Organisation for the Economic Co-operation and Development; http://research.stlouisfed.org/fred2/series/JPNCPIALLMINMEl; accessed January 1, 2015. Long-Term Government Bond Yields: 10-year: Main (Including Benchmark) for Japan [IRLTLT01JPM156N]; Organisation for Economic Co-operation and Development; http://research.stlouisfed.org/fred2/series/IRLTLT01JPM156N; accessed January 1, 2015. Immediate Rates: Less than 24 Hours: Call Money/Interbank Rate for Japan [IRSTCI01JPM156N]; Organisation for Economic Co-operation and Development; http://research.stlouisfed.org/fred2/series/IRSTCI01JPM156N; accessed January 1, 2015. 
The standard error in the per capita GDP growth equation is approximately the same across all three regimes although slightly higher in the No Credibility regime. The standard error in the inflation equation is lower when the central bank follows the Credibility regime and lowest in the ZIRP regime. The biggest differences are in the interest rate equations. The standard error in the policy rate equation falls from 1.79 to 1.37 moving from the No Credibility regime to the Credibility regime (see Tables $1 \mathrm{~A}$ and $1 \mathrm{~B}$ ) and then to nearly zero, 0.14 , in the ZIRP regime. The standard error in the bond rate equation actually rises from 0.62 in the No Credibility regime to 1.07 in the Credibility regime, but then falls to 0.34 in the ZIRP regime.

The bottom panel of Table 2 presents the long-run mean forecasts for the ZIRP model starting from initial conditions in 2007 and 2013. In the model starting from 2007 (2013) initial conditions, the per capita GDP growth rate converges to 1.5 percent in 9 (7) years and the inflation rate converges to -0.1 percent in 5 (5) years. The policy rate converges to 0.1 percent in 7 (2) years, and the bond rate converges to 1.5 percent in 6 (3) years.

\section{PROJECTING INTEREST RATES IN THE POST-CRISIS ECONOMY: 2008-13}

We use the long-run properties of our three times-series models to show the implications of the alternative policy regimes for per capita GDP growth, inflation, and interest rates during the period following the financial crisis. We start at the beginning of 2008 because the housing crisis was already underway. The FOMC officially adopted the ZIRP on December 16, 2008, when it set the policy rate target at 0 to 0.25 percent.

For each regime, we calculate dynamic stochastic forecasts using 10,000 draws of random shocks for the 2008:Q1-2013:Q4 period. We calculate the median forecast and the standard error for each quarter. In Figure 4, the median forecast is displayed as a solid red line and confidence bands of \pm 1 standard deviation are shown as dotted blue lines. The actual values of the predicted variables are shown as black dashed lines. Each column represents a policy regime with four rows representing per capita GDP growth, CPI inflation, the policy rate, and the bond rate.

The top row in Figure 4 shows that none of the models could predict the deep 2007-09 recession. The No Credibility model fails miserably for per capita GDP growth. One reason for this failure is that the trend in per capita output growth was declining throughout the No Credibility period and the downward trend continues into negative territory in the long run. The ZIRP model does the best job of predicting the downturn but still misses the negative growth in 2009. Both the Credibility and ZIRP models predict that per capita GDP growth will converge to 1.5 percent in the long run. The ZIRP model has the tightest confidence bands.

As shown in the second row in Figure 4, none of the models predicted the inflation decline during the recession. The No Credibility model predicts rising and increasingly volatile inflation. The Credibility model converges to a 2.9 percent long-run inflation trend and predicts too much inflation during this period. The ZIRP model, on the other hand, predicts that CPI inflation will converge toward zero and predicts too little inflation. 


\section{Cooke and Gavin}

\section{Figure 4}

\section{Out-of-Sample Forecasts for the Three Monetary Policy Regimes: 2008-13}
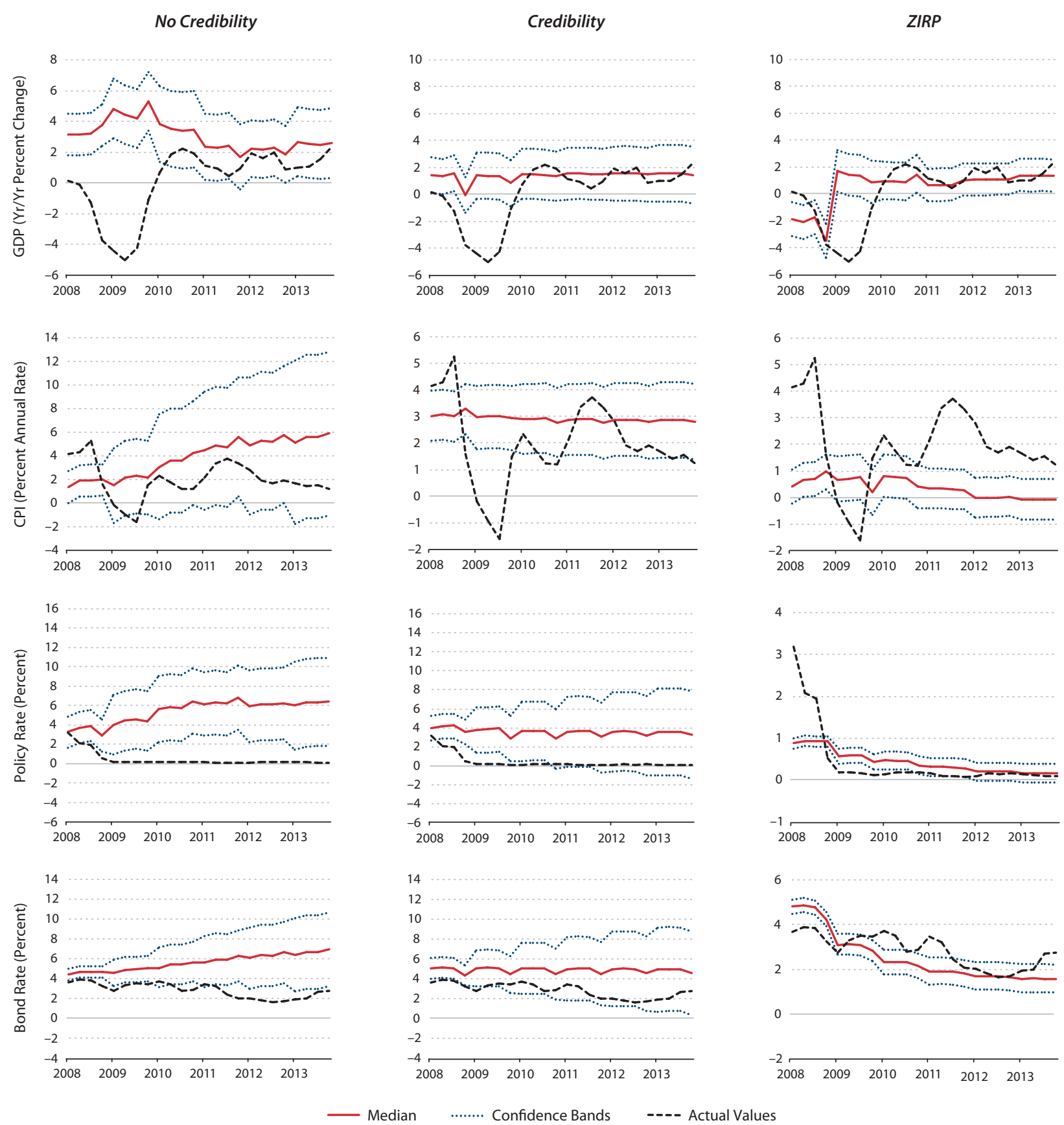

NOTE: The solid red line is the median forecast in 10,000 simulations; the dotted blue lines are the median \pm 1 standard deviation; the dashed black line is the actual value.

SOURCE: Authors' calculations. 


\section{Table 3}

Accuracy of Forecasts

\begin{tabular}{lccccccc} 
& \multicolumn{3}{c}{ Median error } & & \multicolumn{3}{c}{ RMSE } \\
\cline { 2 - 3 } \cline { 7 - 8 } & No credibility & Credibility & ZIRP & & No credibility & Credibility & ZIRP \\
\hline GDP & -2.99 & -1.28 & -0.46 & & 4.05 & 2.76 & 2.20 \\
CPI & -1.89 & -0.97 & 1.60 & & 5.57 & 2.10 & 2.22 \\
RS & -4.90 & -3.15 & 0.01 & & 6.11 & 4.66 & 0.47 \\
RL & -2.77 & -2.05 & 0.31 & & 3.68 & 3.55 & 0.95 \\
\hline
\end{tabular}

The third row in Figure 4 shows the forecasts for the policy rate. The No Credibility model predicts a high, rising, and volatile policy rate. The Credibility model shows the policy rate converging to a 3.4 percent trend with widening confidence bands. The ZIRP model, as expected, is "spot on" with a nearly perfect forecast over the past five years. All the "miss" in this model occurs in 2008, as the rate converges toward zero at the end of the year.

In the fourth row in Figure 4, the No Credibility model predicts a high, rising, and volatile bond rate, just as it does for inflation and the policy rate. The Credibility model predicts the bond rate will converge to 4.8 percent, but the confidence bands continue to widen as the forecast horizon lengthens. The actual bond rate stays below the median forecast but generally within 1 or 2 percentage points. The biggest surprise to us in this figure is the bond rate forecast from the ZIRP model. Here the bond rate forecast is, on average, below the actual rate, but the mean error is small relative to the other forecasts and the model correctly predicts the falling trend.

Table 3 shows the average of the quarterly median and root mean squared error (RMSE) statistics. Although the Credibility model appears to provide a reasonable outlook for per capita GDP growth and the best forecast for inflation, it loses dramatically to the ZIRP model in a comparison of interest rate forecasts. Historically, uncertainty in bond markets has been driven mainly by uncertainty about inflation expectations. ${ }^{11}$ We expected the results from the inflation forecast to be more strongly reflected in performance of the bond rate forecast. The ZIRP model appears to tie down both the long and short rates. The visual evidence is shown clearly in Figure 5, which compares the Blue Chip long-range forecast of the U.S. 10-year government bond rate with the 6-year out-of-sample forecast from the ZIRP model. The Blue Chip longrange forecast for the bond rate is consistent with the 4.8 percent trend predicted by the Credibility model. The ZIRP model is always within 2 standard deviations of the actual rate; the long-run implication is that the bond rate will converge to a record low 1.5 percent if the Fed does not exit the ZIRP regime.

\section{Forecasting Interest Rates in the Transition to Normalcy: 2014-19}

The market and Fed policymakers expect to begin exiting the ZIRP regime in mid-2015. They plan to return to the Credibility regime that characterized policy from 1983 to 2007. For our purpose, we begin the simulations at the beginning of 2014. The forecasts look very similar 


\section{Cooke and Gavin}

\section{Figure 5}

Blue Chip Consensus Forecasts Versus ZIRP Forecasts: 10-Year Treasury Rate (2008-13)

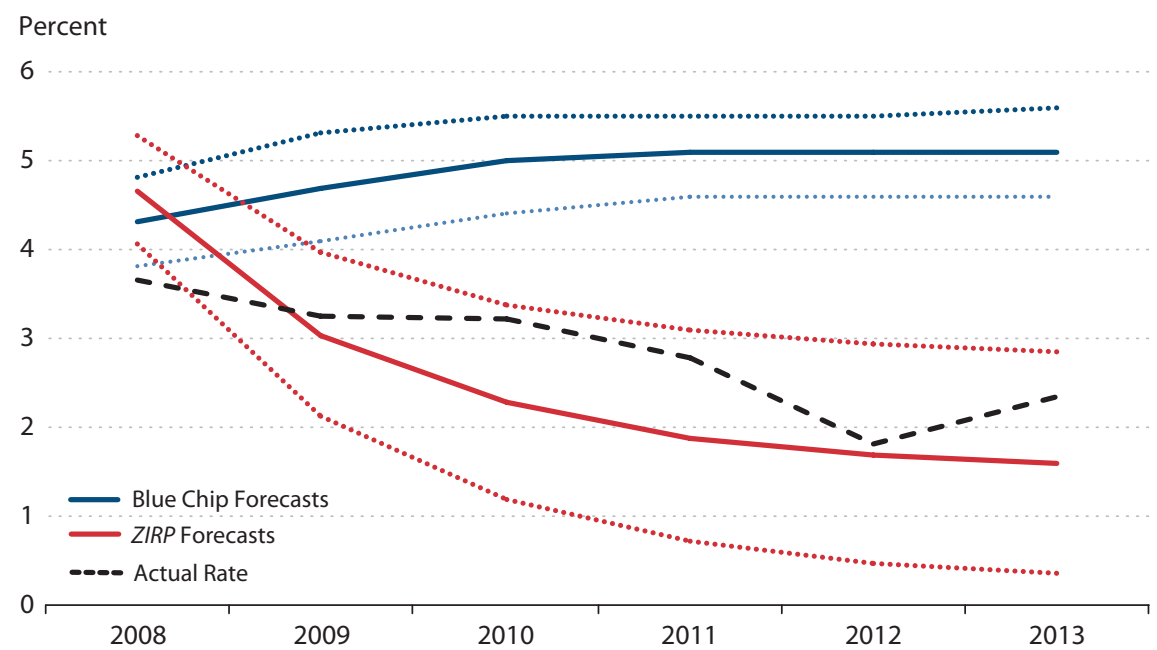

NOTE: For the Blue Chip forecasts, the solid line shows the consensus and the dotted lines show the top 10 and bottom 10 forecasts. For the ZIRP model, the solid line is the median forecast and the dotted lines are \pm 1 standard deviation. The dashed black line shows the actual data. The ZIRP model is estimated using Japanese data from 1995:Q1 through 2007:Q4. All forecasts are out-of-sample. Blue Chip forecasts are as reported on December 1, 2007. We thank Yi Wen for suggesting this figure.

SOURCE: Blue Chip Financial Forecasts published on December 1, 2007, and authors' calculations.

to those in Figure 4, with slightly different initial conditions. The important comparison is between the ZIRP and Credibility regimes. Nevertheless, we also report statistics for the No Credibility regime.

The path of interest rates during the transition to normalcy matters for many reasons. One important concern for the Fed is the effect that interest rates will have on the Fed's interest income and expenses during the transition to normalcy. Carpenter et al. (2013) provide the institutional details and simulations of the transition under alternative interest rate assumptions. Their baseline path for interest rates is based on the Blue Chip Consensus forecast reported in the December 2012 release. Under Carpenter et al.s high interest rate scenario, they assume the paths for the policy rate and the bond rate are 1 percentage point above the Blue Chip Consensus forecast. ${ }^{12}$ Figure 6 shows updated versions of the Blue Chip interest rate forecasts used by Carpenter et al. (2013) in their simulations. For each variable, we define the Blue Chip benchmark (BCB) forecast as the updated forecast plus 1 percentage point. In this section we ask the following questions: "How likely is it that the policy and bond rates will exceed their respective BCB forecast paths in each quarter of our six-year simulation period?" and "How often does the policy rate exceed the bond rate in each quarter of the 10,000 simulations for our three models?" 


\section{Figure 6}

\section{Blue Chip Interest Rate Forecasts (2014-19)}

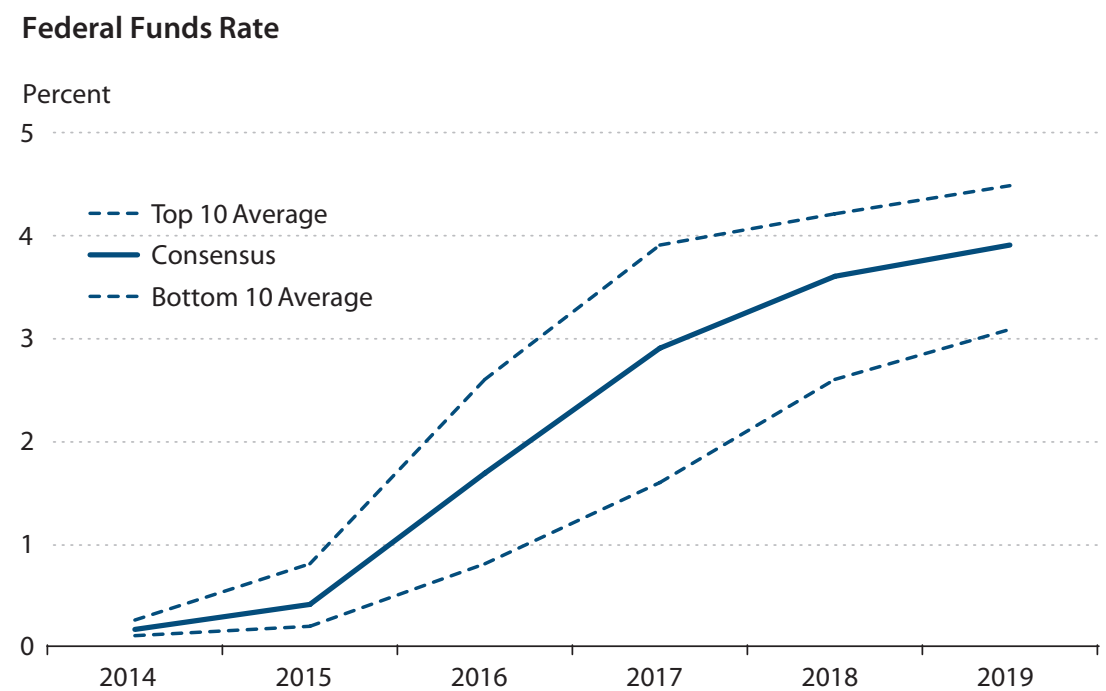

\section{0-Year Government Bond Rate}

Percent

7

--- Top 10 Average

- Consensus

--- Bottom 10 Average

5

4

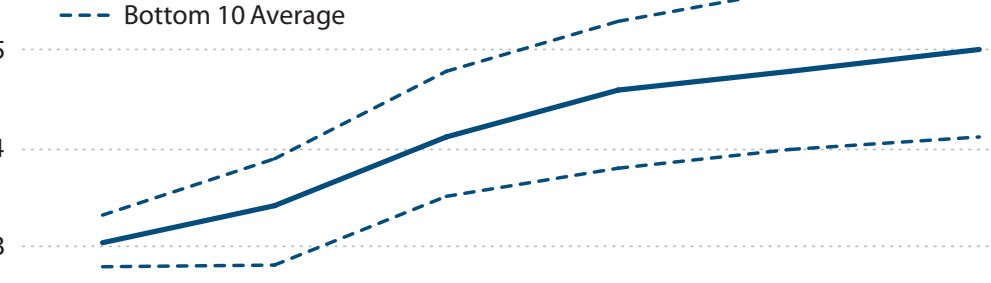

2014

2015

2016

2017

2018

2019

SOURCE: Blue Chip Financial Forecasts published on December 1, 2013. 


\section{Cooke and Gavin}

Our forecasts start with actual conditions at the end of 2013. Figure 7 illustrates the answers to our questions. The top panel shows the percentage of times that the policy rates predicted by the models were above the $\mathrm{BCB}$ forecast for the policy rate. There is a significant likelihood that the policy rates forecasts from both the Credibility and No Credibility models will exceed the BCB forecasts in the first two years after the transition begins. For the No Credibility model (the blue line), the likelihood reaches a maximum of about 90 percent after three years and then declines to about 57 percent by 2019. For the Credibility model (the red line), with its lower trend, the likelihood averages more than 50 percent in the first two years but stabilizes around 30 percent by 2019. For the ZIRP model (the green line), the policy rate forecast never exceeds the BCB forecast.

The middle panel of Figure 7 shows results for the 10 -year government bond rate. The likelihood of the bond rate forecast from the No Credibility model exceeding the $\mathrm{BCB}$ for the bond rate is quite low in the first year: below 10 percent. The likelihood rises gradually to 50 percent by the end of 2017. The pattern for the Credibility model is similar. The likelihood remains below 20 percent in 2014 and rises gradually to 30 percent by 2019 . The bond rate forecasted by the ZIRP model never exceeds the BCB.

The bottom panel of Figure 7 plots the likelihood that the policy rate will be higher than the bond rate. In the No Credibility model, the yield curve is inverted (the policy rate exceeds the bond rate) much of the time in the second through the fourth years of the transition to normalcy. In the Credibility model, the likelihood is much lower, especially in the first year when it is at or below 10 percent. After the second year, the probability of an inverted yield curve rises to a range of 20 to 25 percent. The policy rate is almost never above the bond rate in the ZIRP simulations. During the last three years of the simulations, the number is positive, rising only as high as 19 out of 10,000 simulations in the final year.

\section{Forecast Uncertainty}

Our three policy regimes, No Credibility, Credibility, and ZIRP, were chosen to reflect the different concerns of policymakers regarding the transition to normalcy. The biggest source of uncertainty involves predicting which model will be the right one. A risk-averse decisionmaker will consider the risks involved in a variety of likely outcomes.

We use VAR models to forecast inflation and interest rates. Analysis of forecasts including the 1970s and early-1980s data indicates the VAR forecasts were generally less accurate than more sophisticated forecasts that combined the forecaster's judgment with forecasts from a large econometric model. However, these "more sophisticated" forecasts typically involved periods less than two years into the future. For these short horizons, McNees $(1986,1990)$ finds that while VAR models perform relatively well for some variables, they do not perform well for inflation. He reports that the RMSEs were almost twice as large for the VAR forecasts as for the professional forecasters. The VAR interest rate forecasts for the 3-month Treasury bill were about 33 percent larger than the large-model alternatives.

Reifschneider and Tulip (2008) report that the RMSEs for CPI inflation forecasts for the 1986-2006 period cluster around 1 percent for horizons of 2 to 4 years. These forecasts are tethered to the official forecasts-implicit objectives - of the Fed and the government. This 


\section{Figure 7}

\section{The Likelihood of High Interest Rates: 2014-19}

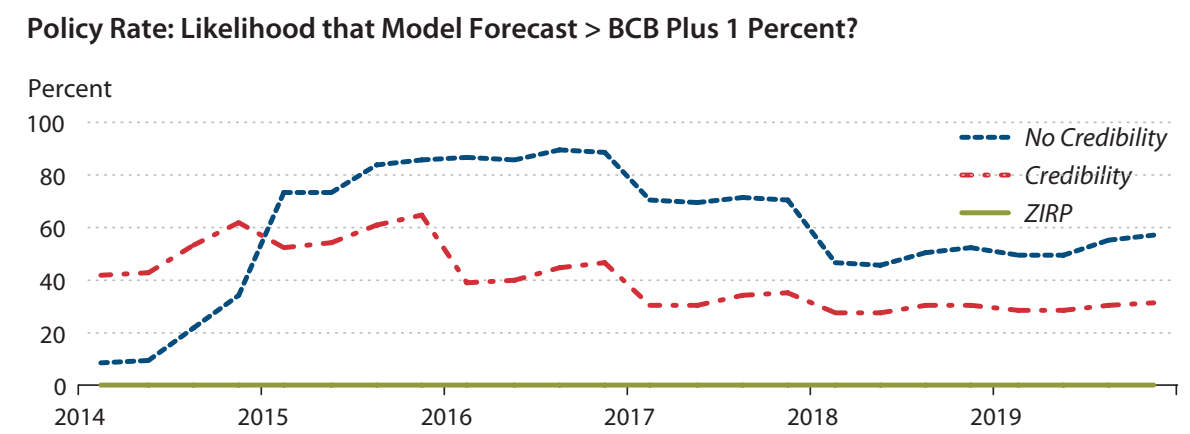

Bond Rate: Likelihood that Model Forecast > BCB Plus 1 Percent?

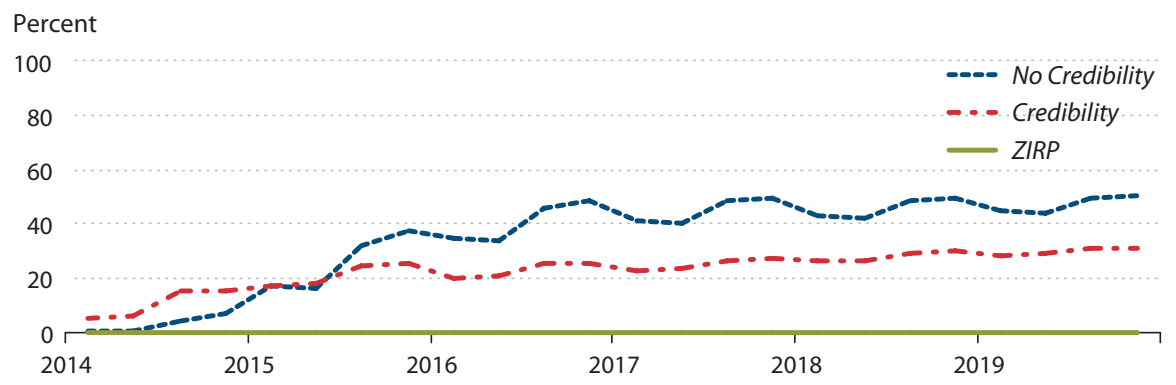

Likelihood that Policy Rate > Bond Rate?

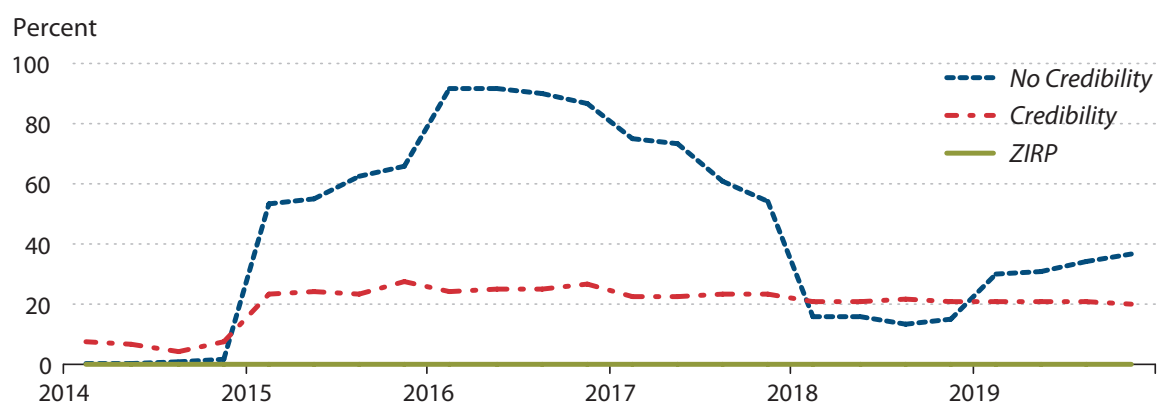




\section{Cooke and Gavin}

level is less than our estimated uncertainty for the Credibility models at a 2-year horizon and much less than the uncertainty associated with the No Credibility models. Even in the Credibility regime, we do not constrain the time-series forecast to the official inflation objective. Although we know that the VAR forecasts are more disperse than typical economic forecasts, they have the advantage of simple construction and easy replication. Furthermore, we are mainly interested in characterizing the alternative regimes and comparing the relative uncertainty across them.

\section{CONCLUSION}

Our first finding is that the ZIRP should be treated as a separate regime with different statistical processes than observed in the United States during the Great Moderation. We assume that the ZIRP could be adequately modeled using Japanese data from 1995 through 2007. Our most startling result is that the ZIRP model, estimated using Japanese data, does the best job forecasting the U.S. data from 2008 through 2013.

A second finding is that the ZIRP regime leads to low and stable long-term bond rates and lower-than-expected inflation. The ZIRP model underpredicts inflation, which we attribute to the fact that policymakers and markets expect the FOMC to return to the Credibility model with a 2 percent inflation target. As noted, the 2 percent inflation target is not consistent with a ZIRP regime and the longer the FOMC maintains this regime, the farther the trend inflation rate will fall below the target.

A third finding is that the No Credibility model has terrible implications for the post-crisis period. The time-series properties of this regime strongly recommend against this model as a policy choice. The bad economic outcomes of this regime make it imperative for policymakers to take special care to avoid it. Worldwide, this policy regime has been observed in countries that lose control of their federal government budget process. When they lose the ability to curb spending or raise taxes, such governments print money to pay for spending.

Our fourth, and perhaps less obvious, finding is that any attempt to return to the Credibility regime will likely involve higher and more volatile interest rates, reminiscent of the volatility during the taper tantrum of May and June 2013 when then-Fed Chair Ben Bernanke announced that the Fed would gradually slow its large-scale purchases of long-term securities. Our analysis suggests that lifting off the zero lower bound will involve a period of heightened uncertainty about interest rates at both short- and long-term horizons.

We do not draw any firm conclusions from these experiments about the effects of the ZIRP on the real economy. In our models, the per capita GDP growth rate converges to 1.5 percent at an annual rate in both the Credibility and the ZIRP models. Our main concern is that uncertainty about which regime the economy will converge to creates a headwind that keeps the economy operating below its efficient level. A decision to adopt the ZIRP model should be accompanied by an explicit decision to allow inflation to run at or below zero percent, as the Japanese have done. Our analysis suggests that their recent decision to adopt a 2 percent inflation target is doomed to fail if they are not willing to raise interest rates to some normal level that is approximately equal to the sum of the inflation target and per capita real GDP growth. 
The problem is that over time, if the central bank fixes the nominal interest rate and allows real factors to determine the real interest rate, then according to the Fisher equation, inflation will adjust to clear the bond market.

From the point of view of money and bond markets, the FOMC has been replicating Japan's ZIRP regime. The only circumstance in which future interest rates are not likely to be a problem is if the ZIRP policy is the new normal. In our simulations, the policy rate exceeded the bond rate about 20 to 25 percent of the time in the Credibility regime. In the ZIRP model, the yield curve was almost never inverted. If normalization is, as planned, a return to the Credibility model with a historically "normal"-sized balance sheet for the Fed, then one should plan for a scenario in which higher interest rates will complicate the normalization process. 


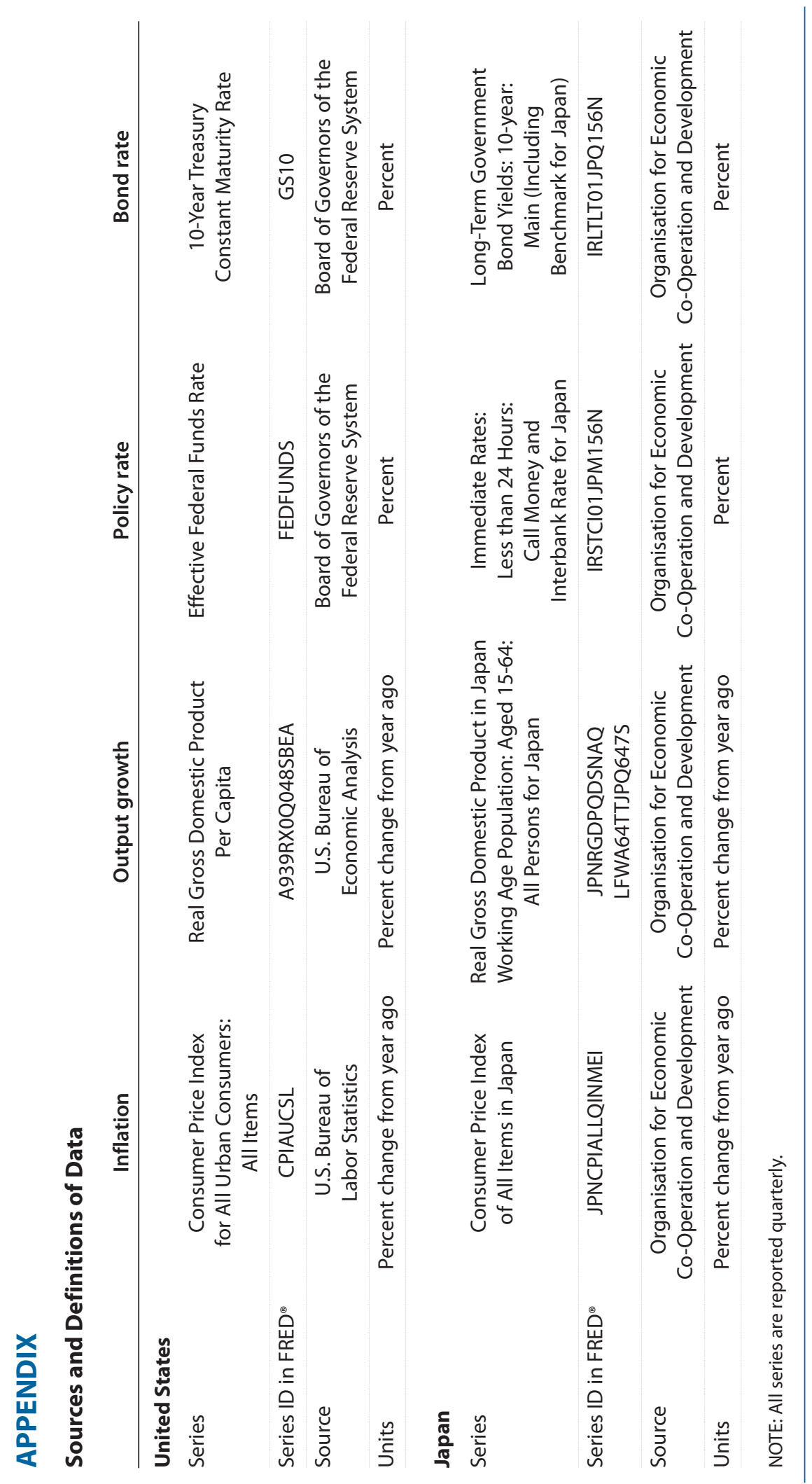




\section{NOTES}

1 Note that the Census Bureau projects that the U.S. population will grow at an average annual rate of 0.8 percent from 2015 to 2021, implying that FOMC members project that per capita output will grow between 1.4 and 2.2 percent. See Table 1 at http://www.census.gov/population/projections/data/national/2014/summarytables.html.

2 See, for example, the arguments by Calomiris (2012) in his comments on Campbell et al. (2012). More recently, Meltzer (2014) explains the high-inflation risk posed by the Fed's balance sheet policy.

3 See Gavin and Kydland (1999) for evidence comparing the properties of nominal and real time-series data before and after the Volcker monetary policy reform. They show that the change in monetary policy regime had a statistically significant impact on the time-series properties of the nominal data (prices, money, and velocity), but not on the real quantities (output, consumption, investment, and hours worked).

4 See the appendix for a more detailed description of data sources.

5 See Nelson (2004), who explains why many economists and policymakers during this period did not consider it important for the Fed to put much emphasis on the goal of price stability.

6 The model has converged when it is less than one-tenth of a percentage point from the long-run value.

7 See Goodfriend (1993) for an essay on inflation scares.

8 See Bullard (2010) for a survey of economic theories that show how an economy can become "trapped" at the zero lower bound. See Cooke and Gavin (2014, pp. 8-9) for an introductory discussion of the Fisher equation.

9 For evidence of the contrary-showing weak empirical links among interest rates, inflation, and the real economysee Staiger, Stock, and Watson (1997) and Stock and Watson (2003). For a good explanation about how beliefs about such relationships may drive shifts in the policy regime, see Cho, Williams, and Sargent (2002).

${ }^{10}$ We did not investigate the possibility that U.S. data from the 1930 s may fit this definition of a ZIRP regime.

${ }^{11}$ See Gallmeyer et al. (2007).

${ }^{12}$ See Figure 6. This is the high interest benchmark used by Carpenter et al. (2013) when simulating alternative exit strategies. On page 26, they write "Although this shock—particularly the parallel shift-is an unlikely outcome, we present it to show the interest rate sensitivity of the portfolio."

\section{REFERENCES}

Bullard, James. "Seven Faces of 'The Peril.'” Federal Reserve Bank of St. Louis Review, September/October 2010, 92(5), pp. 339-52; http://research.stlouisfed.org/publications/review/10/09/Bullard.pdf.

Calomiris, Charles W. "Comments and Discussion." Brooking Papers on Economic Activity, Spring 2012, pp. 55-63.

Campbell, Jeffrey R.; Evans, Charles L.; Fisher, Jonas D.M. and Justiniano, Alejandro. "Macroeconomic Effects of Federal Reserve Forward Guidance." Brooking Papers on Economic Activity, Spring 2012, pp. 1-54.

Carpenter, Seth B.; Ihrig, Jane E.; Klee, Elizabeth C.; Quinn, Daniel W. and Boote, Alexander H. "The Federal Reserve's Balance Sheet and Earnings: A Primer and Projections." Finance and Economics Discussion Series No. 2013-01, Federal Reserve Board, September 2013; http://www.federalreserve.gov/pubs/feds/2013/201301/201301 pap.pdf.

Cho, In-Koo; Williams, Noah and Sargent, Thomas J. "Escaping Nash Inflation." Review of Economic Studies, January 2002, 69(1), pp. 1-40; http://restud.oxfordjournals.org/content/69/1/1.full.pdf+html.

Cooke, Diana A. and Gavin, William T. "The Ups and Downs of Inflation and the Role of Fed Credibility." Federal Reserve Bank of St. Louis Regional Economist, April 2014, pp. 5-9; https://www.stlouisfed.org/publications/regional-economist/april-2014/the-ups-and-downs-of-inflation-andthe-role-of-fed-credibility.

Gallmeyer, Michael F.; Hollifield, Burton; Palomino, Francisco J. and Zin, Stanley E. “Arbitrage-Free Bond Pricing with Dynamic Macroeconomic Models." Federal Reserve Bank of St. Louis Review, July/August 2007, 89(4), pp. 305-26; http://research.stlouisfed.org/publications/review/07/07/Gallmeyer.pdf. 


\section{Cooke and Gavin}

Gavin, William T. and Kydland, Finn E. "Endogenous Money Supply and the Business Cycle." Review of Economic Dynamics, April 1999, 2(2), pp. 347-69.

Goodfriend, Marvin. "Interest Rate Policy and the Inflation Scare Problem: 1979-1992." Federal Reserve Bank of Richmond Economic Quarterly, Winter 1993, 79(1), pp. 1-23;

https://www.richmondfed.org/publications/research/economic_quarterly/1993/winter/pdf/goodfriend.pdf.

Ito, Takatoshi and Mishkin, Frederic S. "Two Decades of Japanese Monetary Policy and the Deflation Problem." NBER Working Paper No. 10878, National Bureau of Economic Research, November 2004; http://www.nber.org/papers/w10878.pdf.

Lindsey, David E; Orphanides, Athanasios and Rasche, Robert H. "The Reform of October 1979: How It Happened and Why." Federal Reserve Bank of St. Louis Review, March/April 2005, 87(2 Part 2), pp. 187-235; http://research.stlouisfed.org/publications/review/05/03/part2/Lindsey.pdf.

Lucas, Robert E. Jr. "Econometric Policy Evaluation: A Critique." Carnegie-Rochester Conference Series on Public Policy, January 1976, 1(1), pp. 19-46.

McNees, Stephen K. "Forecasting Accuracy of Alternative Techniques: A Comparison of U.S. Macroeconomic Forecasts." Journal of Business and Economic Statistics, January 1986, 4(1), pp. 5-15.

McNees, Stephen K. "The Role of Judgment in Macroeconomic Forecasting Accuracy." International Journal of Forecasting, October 1990, 6(3), pp. 287-99.

Meltzer, Allan H. “How the Fed Fuels the Coming Inflation.” Wall Street Journal, May 6, 2014; http://online.wsj.com/news/articles/SB10001424052702303939404579527750249153032.

Nelson, Edward. "The Great Inflation of the Seventies: What Really Happened?" Working Paper No. 2004-001, Federal Reserve Bank of St. Louis, January 2004; http://research.stlouisfed.org/wp/2004/2004-001.pdf.

Reifschneider, David and Tulip, Peter. "Gauging the Uncertainty of the Economic Outlook From Historical Forecasting Errors." Finance and Economics Discussion Series Working Paper No. 2007-60, Federal Reserve Board, August 2007; http://www.federalreserve.gov/pubs/feds/2007/200760/200760pap.pdf. August 2008 update; http://www.petertulip.com/Reifschneider_Tulip_2008.pdf.

Staiger, Douglas; Stock, James H. and Watson, Mark W. "The NAIRU, Unemployment and Monetary Policy." Journal of Economic Perspectives, Winter 1997, 11(1), pp. 33-49; http://pubs.aeaweb.org/doi/pdfplus/10.1257/jep.11.1.33.

Stock, James H. and Watson, Mark, W. "Forecasting Output and Inflation: The Role of Asset Prices." Journal of Economic Literature, September 2003, 41(3), pp. 788-829; http://pubs.aeaweb.org/doi/pdfplus/10.1257/002205103322436197. 